\title{
Gestão ambiental e desenvolvimento regional: uma análise da indústria fumageira ${ }^{*}$
}

\begin{abstract}
The present study is inserted in the field of regional development and makes an analysis of the environmental management performed by the tobacco industries located in the region of Vale do Rio Pardo in the State of Rio Grande do Sul (Brazil), which has the particularity of being the main tobacco producer in Brazil. It has been realized that the tobacco industry is recognizing the importance of the environmental aspect in its decisions and, in this way, besides the recognition in the economic context, it is showing concern about the environmental managing, through initiatives that aim the preservation of the environment and the improvement of quality of life of its employees as well as of the worker in the field, the farmer. As work methodology it was decided to do initially a theoretical essay involving the systemic approach and the regional development, followed by a case study with a description of the environmental management practices of the industries that cause impact in the tobacco farmer's activities.
\end{abstract}

Keywords: environmental managing, regional development, tobacco industry.

\section{Resumo}

O presente estudo se insere no campo de desenvolvimento regional, o qual faz uma análise da gestão ambiental praticada pelas indústrias fumageiras instaladas na região do Vale do Rio Pardo do Estado do Rio Grande do Sul, que se particulariza como a principal produtora de fumo do Brasil. Constata-se que a indústria fumageira está reconhecendo a importância da questão ambiental e, nesse sentido, além de se destacar no contexto econômico, vem demonstrando sua preocupação com a gestão do meio ambiente, divulgando iniciativas que visam à preservação do meio ambiente e à melhoria da qualidade de vida tanto de seus trabalhadores como também do homem do campo, o fumicultor. Como metodologia de trabalho, adotou-se inicialmente fazer um ensaio teórico envolvendo a abordagem sistêmica e o desenvolvimento regional, seguido de um estudo de caso, com uma descrição das práticas de gestão ambiental adotadas pelas indústrias que impactam nas atividades do fumicultor.

Palavras-chave: gestão ambiental, desenvolvimento regional, indústria fumageira. 


\section{Introdução}

A preservação do meio ambiente e a gestão ambiental vêm obtendo maior importância na indústria brasileira. Os resultados da Pesquisa Gestão Ambiental na Indústria Brasileira, realizada em 1998 pelo Banco Nacional de Desenvolvimento Econômico e Social (BNDES), pela Confederação Nacional da Indústria (CNI) e pelo Serviço Brasileiro de Apoio às Micro e Pequenas Empresas (SEBRAE), indicam que aproximadamente $85 \%$ das médias e grandes empresas adotam algum procedimento de gestão ambiental.

Outra evidência a ser considerada no Brasil é a crescente busca da certificação ambiental, por meio da ISO 14001 que, em 2003, atingiu a marca de 1000 empresas certificadas, cujo crescimento se acentuou nos dois últimos anos. Segundo estatísticas das certificaçōes por região, as empresas situadas na região sul do Brasil possuem 17,2\% das certificaçôes, ocupando a segunda posição, ao lado da região sudeste, que detém 60\% (Revista Meio Ambiente Industrial, 2003).

Entretanto, os problemas ambientais enfrentados atualmente não são novos, apenas a compreensão da sua complexidade é recente. Tendo-se presente a preocupação de como o desgaste ambiental pode impedir ou reverter o desenvolvimento econômico e social, especificamente na questão do desenvolvimento regional, Becker (2001) ressalta que, entre os múltiplos e complexos caminhos e descaminhos decorrentes da necessidade de tornar sustentável o desenvolvimento, a degradação ambiental é um dos mais desafiadores. Operar de forma equilibrada com o meio ambiente constitui-se numa questão primordial que pressiona as organizações, sejam estas públicas ou privadas.

Professora do Departamento de Ciências Contábeis, Universidade de Santa Cruz do Sul (Brasil). E-mail: mfrey@unisc.br

Professor dos Programas de Pós-Graduação em Desenvolvimento Regional, UNISC/Programa de PósGraduação em Administração e Engenharia de Produção, Universidade Federal de Santa Maria (Brasil). E-mail: wittmann@profwittmann.com

** Enviado el 1 de marzo de 2005, aprobado el 20 de marzo de 2006.
Na visão de Kinlaw (1997: 19), "a maneira como as organizaçôes irão responder aos muitos desafios decorrentes desta questão vai determinar, em muito, sua situação competitiva e sua sobrevivência”. O entendimento de Kinlaw (1997) encontra respaldo e base nos estudos sobre competitividade realizados por Porter e Van der Linde (1999), que, ao discutirem a regulamentação ambiental, apontam que a maneira como as empresas respondem aos problemas ambientais seja, talvez, de fato um indicadorchave da sua competitividade.

As empresas, que se ajustam a esse novo ambiente de negócios, percebem cada vez mais que, diante das questões ambientais, há novas estratégias concorrenciais associadas a processos de renovação contínua. Essas questões, segundo Sanches (2000), podem ser impostas por meio de regulamentações ambientais, oriundas de uma imagem pública negativa e ou gerenciada internamente, mediante mecanismos de auto-regulação ou por ações individuais, assumindo uma postura pró-ativa.

$\mathrm{Na}$ análise de Layrargues (2000), o setor empresarial vem promovendo uma mudança desde o início da década de 90, quando assumiu uma atitude positiva sobre o meio ambiente, não mais compulsoriamente, por causa da legislação ambiental e sim, por vislumbrar oportunidades de negócios ao agregar a variável ambiental.

O interesse pela qualidade ambiental foi reforçado com a globalização da economia, que desenvolveu um mercado mundial sem fronteiras, provocando um forte acirramento da competição empresarial, alicerçada no domínio das inovaçōes tecnológicas que passaram a utilizar critérios ambientais. A abertura dos mercados pela globalização da economia acabou criando a série ISO 14000, "mecanismo capaz de atuar como um fator regulador da competição, normatizador das práticas de marketing e limitador das barreiras comerciais no mercado" (Layrargues, 2000: 82).

Especificamente em relação ao setor fumageiro que, segundo entendimento de Etges (2001), imprime identidade à região do Vale do Rio Pardo como a principal produtora de fumo do país, verifica-se que a questão ambiental tem recebido atenção na condução dos negócios. Nesse contexto, o presente 
artigo descreve os principais procedimentos de gestão ambiental vinculados ao sistema integrado de produção das indústrias fumageiras instaladas na região do Vale do Rio Pardo, no qual inicialmente apresenta-se um ensaio teórico envolvendo a abordagem sistêmica e o desenvolvimento regional. Como procedimento para o levantamento de dados optou-se pelo estudo de caso, que possibilitou lidar com uma variedade de evidências, no qual foram utilizados a análise de documentos, entrevistas e observações diretas.

\section{Abordagem sistêmica e a gestão ambiental}

A consciência, que se retrata atualmente sobre o meio ambiente e o desenvolvimento sustentável, é resultado de uma construção que passou pela contribuição dos movimentos ambientalistas mundiais e pela elaboração de um pensamento oficial do Estado. As mudanças na gestão ambiental não ficaram a mercê das iniciativas empresariais; estas, pelo contrário, se ajustaram às novas legislações impostas pelo Estado e às pressōes da sociedade sobre esse problema, influenciadas pelas principais conferências internacionais sobre o meio ambiente e pelos estudos realizados desde 1970, como o Relatório do Clube de Roma-limites do crescimento; a Declaração de Estocolmo; o Relatório de Brundtland-Nosso futuro comum; a Declaração do Rio; e a Agenda 21.

O pensamento sobre o desenvolvimento sustentável tem sua base no Relatório de Brundtland-Nosso Futuro Comum, o qual afirma que o desenvolvimento sustentável é aquele que "atende às necessidades do presente sem comprometer a possibilidade de as gerações futuras atenderem suas próprias necessidades" (CMMAD, 1991: 46). De acordo com Bello (2001), foi no Relatório Nosso Futuro Comum que apareceu a primeira chamada para a indústria desenvolver efetivamente sistemas de gerenciamento ambiental.

Para as empresas, segundo Maimon (1996), as vantagens do sistema de gestão ambiental são organizacionais, redutoras de custos de operação, minimizadoras de acidentes e competitivas. A gestão ambiental busca, por meio de planejamento organizacional, encontrar novas alternativas que tornem as empresas mais competitivas e com menor incidência na geração de problemas ambientais. Grande parte da redução do custo de operação, na gestão ambiental, é obtida a partir da eliminação de resíduos industriais que são gerados por meio de processos ineficientes e da má utilização da matéria-prima que, além de não adicionarem valor ao produto, geram despesas quanto à sua destinação, aumentando inclusive a taxa de risco ambiental.

O gerenciamento de sistemas ambientais das empresas é resultado do mercado globalizado que passou a exigir das empresas, certificados de preservação do meio ambiente, ressaltando que "as empresas que respeitam as leis e defendem a ecologia e fazem algo por ela, podem conquistar os certificados oferecidos pela norma ISO série 14000 . Assim adquirem uma enorme vantagem competitiva, pois conseguem o respeito dos consumidores".

O processo de implementação da série ISO 14000 passa pela elaboração de Sistemas de Gestão Ambiental (SGA), previstos na NBR ISO 14001. Na opinião de Lerípio (2000: 28), esse processo se constitui numa estratégia "para que o empresário, em processo contínuo, identifique oportunidades de melhorias que reduzam os impactos das atividades de sua empresa sobre o meio ambiente, de forma integrada à situação de conquista de mercado e lucratividade".

A ISO 14001, assim como as demais normas internacionais de gestão ambiental, tem por objetivo prover as organizações com um sistema de gestão ambiental passível de integração com qualquer outro requisito de gestão, de forma a auxiliá-las a alcançar seus objetivos ambientais e econômicos. A principal finalidade da ISO 14001 é equilibrar a proteção ambiental e a preservação da poluição com as necessidades socioeconômicas da organização.

Entretanto, um dos problemas apontados com os quais as organizações se defrontam na gestão ambiental é a visão segmentada que a maioria possui de si mesma. No entendimento de Andrade, Carvalho e Tachizawa (2000), as organizaçōes devem adotar uma visão sistêmica, abrangente e holística, que possibilite visualizar as relações causa e efeito, o início, o meio e o fim, ou seja, as interrelações entre recursos captados, processos e valores por elas obtidos. 
Segundo Capra et al. (1999: 88), a gestão ambiental, no seu sentido mais profundo e amplo, denominada pelos autores como gerenciamento ecológico, envolve a passagem do pensamento mecanicista para o pensamento sistêmico, no qual "um aspecto essencial dessa mudança é que a percepção do mundo como máquina cede lugar à percepção do mundo como sistema vivo". Para os autores, essa mudança refere-se à percepção que as pessoas possuem da natureza, do organismo humano, da sociedade e, portanto, à percepção que se tem de uma organização: "As empresas são sistemas vivos, cuja compreensão não é possível apenas pelo prisma econômico. Como sistema vivo, a empresa não pode ser rigidamente controlada por meio de intervenção direta, porém pode ser influenciada pela transmissão de orientações e emissão de impulsos" (Capra et al., 1999: 88).

O enfoque sistêmico para Dias (1985) é totalmente compatível com o antigo (Gregos), no qual o conhecimento acumulado pela humanidade não era deixado de lado, mas sim ampliado pela possibilidade de serem descobertas relações que explicassem melhor o funcionamento do todo. Já com Descartes, passou a predominar a especialização gerada pela fragmentação das ciências, baseada no modelo cartesiano que privilegiava a linearidade do conhecimento; entretanto, hoje se estimulam a interdisciplinaridade e a transdisciplinaridade que privilegiam a integração de campos de estudo. Para Schoderbek, a Ciência de Sistemas é composta de dois campos principais de desenvolvimento teórico: a Teoria Geral de Sistemas, cujo pai é Ludwig von Bertalanffy, que se ocupa do crescimento e da evolução dos sistemas, e a Cibernética, cujo pai é Norbert Wiener, entendida como a ciência do controle e da comunicação no animal e na máquina (apud Dias, 1985).

Segundo Churchman (1972), existem vários entendimentos e definiçôes do enfoque sistêmico. Ao discutir "sistemas", o autor examina quatro idéias diferentes relativas ao enfoque sistêmico, respectivamente: a visão da eficiência, da ciência, do uso dos sentimentos humanos e dos antiplanejadores. Embora o termo "sistema" tenha sido definido de várias maneiras, Churchman (1972: 50) afirma que todos os definidores concordam que um sistema "é um conjunto de partes coordenadas para realizar um conjunto de finalidades".
O princípio da transdisciplinaridade, também presente na teoria dos sistemas, representa, segundo Seiffert (2002), uma importante característica que vem ao encontro de necessidades que surgem ao se lidar com as variáveis ambientais e seus inter-relacionamentos com o contexto organizacional. Conforme a autora, estudiosos da questão ambiental, como Sacks, Godart e Leff, reconhecem na abordagem sistêmica uma matriz de organização do conhecimento interdisciplinar, necessária ao planejamento e à análise da gestão ambiental.

Para as organizações, a visão sistêmica representa uma forma de analisar o meio ambiente e definir cenários prováveis de longo prazo. Conforme Capra et al. (1999), a realidade não deve ser vista apenas como uma reunião de objetos separados, mas sim como uma teia inseparável de relaçôes, incluindo a vida: "Os sistemas vivos compreendem organismos individuais, sistemas sociais e ecossistemas, e constituem conjuntos integrados inseridos em conjuntos maiores, dos quais dependem. Embora possamos discernir partes individuais em qualquer sistema, a natureza do todo é sempre diferente da simples soma das partes. A natureza de qualquer sistema vivo, incluída aí a organização de negócios, deriva das relaçôes entre seus componentes e das relações do sistema todo com seu ambiente".

Segundo Andrade, Carvalho e Tachizawa (2000: 90), "a organização deve ser visualizada como um conjunto de partes em constante interação, constituindo-se em um todo orientado para determinados fins, em permanente relação de interdependência com o ambiente externo". Na concepção de Backer (1995), desde o homo sapiens, a interação entre atividade humana e o seu meio ambiente foi fator dominante na moldagem de um pelo outro. Entretanto, quando essa atividade, por força da sua organização, começou a denominar-se "empresa", ela tornou-se inevitavelmente um elo essencial na cadeia de equilíbrio do meio ambiente como um todo.

A empresa não é um sistema que possa ser separado do resto do ecossistema. Ao contrário, como caracteriza Backer (1995), ela é o lugar de convergência e, muitas vezes, de conflagração das contradiçôes e dos conflitos entre grupos e pessoas com interesses parcialmente opostos. As contradições que se deflagram dentro de uma organização são, na visão 
de Capra et al. (1999), sinais de sua variedade e vitalidade e dessa forma contribuem para a viabilidade do sistema, afirmando que, sem conflitos, não há desenvolvimento algum.

De acordo com Andrade, Carvalho e Tachizawa (2000), o enfoque sistêmico é o embasamento filosófico do modelo de gestão ambiental, no qual a compreensão do todo é mais importante do que o mero conhecimento das partes. Nesse enfoque, a organização é considerada como um macrossistema aberto que interage com o meio ambiente, convertendo recursos em produtos, bens e serviços, em consonância com seu modelo de gestão, missão, crenças e valores corporativos.

\section{Desenvolvimento regional e gestão ambiental na fumicultura}

Freqüentemente a idéia de desenvolvimento é reduzida a desenvolvimento econômico, esse entendido como um processo de crescimento econômico, reduzido a indicadores quantitativos como renda e nível de emprego, capacidade produtiva e população. Muito se tem discutido sobre uma concepção alternativa de desenvolvimento, oriunda, segundo Lima (1997), dos resultados insatisfatórios e das contradições reveladas na experiência prática e nas construçôes teóricas sobre desenvolvimento econômico, baseado no paradigma único de crescimento, que findaram convergindo para a concepção de desenvolvimento sustentável.

Paralelamente à concepção de desenvolvimento sustentável, tem ressurgido às discussões o conceito de região, explicada, segundo Castro (1994: 158), pela "crescente importância da escala planetária na organização da economia, das finanças, das redes de poder que têm, paradoxalmente, reforçado a importância das decisóes nas escalas regionais e locais". Em relação às discussões em torno da conceituação de região, Etges (2001: 351) também salienta que as mesmas vêm se acentuando ao longo da última década, particularmente no sul do Brasil onde, através de várias iniciativas, "a discussão da regionalização, visando à descentralização político-administrativa, através da gestão democrático-participativa do território, está na ordem do dia”.

No entendimento de Etges (2001), a conceituação de região tem duas fases distintas: a primeira é oriunda do processo de ocupação do território, no qual as condiçôes físicas ou naturais praticamente determinavam o uso do território; e a segunda identifica a região pelas suas marcas que se imprimem à medida que a sociedade vai se apropriando de determinado território. Essas marcas, segundo a autora, revelam o uso que foi dado e que vem sendo dado atualmente a esse território, determinado por interesses econômicos, sociais, políticos e culturais. Theis e Renck (2002) tratam o conceito de região como uma localidade de um lugar, que corresponde a uma área geográfica de extensão subnacional, que apresenta um determinado grau de desenvolvimento, associado à presença de uma comunidade de indivíduos e de suas atividades socioeconômicas.

Especificamente, no que se refere à desenvolvimento regional, os autores afirmam "que se trata do processo de acumulação que tem lugar no espaço de uma dada região; em outros termos, por desenvolvimento regional se entende o processo localizado de mudança social sustentável, que tem como propósito o progresso permanente de uma comunidade [e de seus respectivos membros] que vive num determinado espaço regional" (Theis e Renck, 2002: 5).

Considerando que o debate sobre desenvolvimento regional vem ocupando o meio acadêmico e os discursos de políticos, Mattedi e Theis (2002) ampliam o conceito, assumindo que o mesmo contém, além de um caráter objetivo, uma dimensão normativa. Concluem que o desenvolvimento regional é uma categoria interdisciplinar que favorece a aproximação de diversas áreas de conhecimento. Nesse sentido, Becker (2001), ao discutir e refletir sobre a economia política da regionalização do desenvolvimento contemporâneo, também afirma já não ser mais possível se fazer a análise de uma determinada dinâmica de desenvolvimento regional munido de um único instrumental teórico-metodológico disciplinar.

Para Becker (2001: 40), o desenvolvimento regional deve ser entendido como um processo de transformações econômicas, sociais e políticas, "cuja dinâmica é imprimida desde 'de dentro e por iniciativa própria' dos agentes locais, manifesta nas ' $m u-$ danças estruturais ou qualitativas' que um desenvolvimento regional sofre a partir de 'alterações 
endógenas'". Em outros termos, descreve Becker que o processo de desenvolvimento recente, em que reina absoluto o modo de produção capitalista, tem no desenvolvimento local sua forma elementar. Exemplificando, afirma que "o desenvolvimento local é a aparência singular, elementar e individualizada da complexa trama/rede de determinações e relações que organizam e dinamizam o desenvolvimento contemporâneo globalizado" (Becker, 2001: 40).

Em sua análise, Becker (2001: 32) salienta a necessidade de se tornar sustentável o desenvolvimento regional, no qual se têm dois grandes desafios: os relativos ao mundo do trabalho e os decorrentes da degradação ambiental: "Simultaneamente, trabalho, enquanto base social do processo de desenvolvimento humano, e natureza, enquanto base natural do processo de desenvolvimento regional, transformaram-se em desafios ambientais da localização do desenvolvimento capitalista".

Becker (2001) parte do pressuposto de que o processo de regionalização socioambiental do desenvolvimento capitalista é, por um lado, necessidade do processo de globalização econômica e, por outro, possibilidade de um desenvolvimento local diferenciado e diferenciador.

No contexto de desenvolvimento regional, inclui-se na discussão a gestão ambiental no setor fumageiro. A produção do fumo, segundo entendimento de Etges (2001), imprime identidade à região do Vale do Rio Pardo, que se particulariza frente às demais regiōes do Estado do Rio Grande do Sul, consolidando-se como a principal produtora de fumo do Brasil. Além de se destacar no contexto econômico, nos últimos anos, o setor fumageiro vem demonstrando sua preocupação com a questão ambiental, divulgando iniciativas que visam à preservação do meio ambiente e à melhoria da qualidade de vida do homem do campo e buscando a certificação ambiental, através da ISO 14001.

As iniciativas que vêm sendo divulgadas estão diretamente ligadas à produção do fumo, junto aos fumicultores vinculados, como redução e eliminação de agrotóxicos, introdução do uso de agentes de controle biológico, uso de cultivares resistentes às principais doenças, monitoramento de resíduos de pesticidas, uso de equipamentos de proteção individual (EPIs), adoção de práticas de preservação e con- servação do solo e reflorestamento e preservação de matas nativas.

Um aspecto importante na definição de prioridades e estratégias para a gestão ambiental, em nível de empresa, é a identificação e a avaliação dos impactos ambientais causados pelas suas atividades. Para essa finalidade, um instrumento que pode ser utilizado é a avaliação do "ciclo de vida" dos produtos. Essa metodologia implica a avaliação dos impactos ambientais gerados pelo produto da empresa em todo o seu ciclo de vida, desde os insumos que são utilizados para a sua elaboração, passando pelos processos de transformação, pela distribuição, utilização e disposição final dos produtos. Com base nessa metodologia, os impactos de uma indústria fumageira envolveriam desde o processo de produçáo do fumo em folha, no qual se verifica a aplicação de agrotóxicos e seus efeitos sobre o meio ambiente e a saúde dos produtores, a queima de madeira para secagem das folhas, passando pelo beneficiamento e pela fabricação do cigarro, até o consumo dos cigarros e seus efeitos sobre a saúde e a disposição final dos resíduos e das embalagens (Souza, 2000).

Conforme estudos realizados, vários são os motivos que têm conduzido as ações de gestão ambiental nas empresas. No início da década de 90, Neder, citado por Souza (2000), pesquisou organizaçōes industriais de grande porte de todo país, nas quais constatou que as ações ambientais das empresas concentravam-se na modernização dos sistemas de controle da poluição, como resultado das exigências da regulamentação ambiental. Em outra pesquisa realizada em 1998 pelo CNI/BNDES/SEBRAE, com empresas de todo o país, de todos os setores e tamanhos, as exigências das regulamentações ambientais ainda figuram entre as principais razões da adoção de procedimentos ambientais. No entanto, a maioria das indústrias de médio e grande porte, tem na política social da empresa uma razão mais destacada para a melhoria da performance ambiental da empresa. As grandes empresas também enfatizaram que o acesso à exportação e o atendimento ao consumidor atento à preocupação ambiental são razôes para a adoção de procedimentos de gestão ambiental.

Souza (2000) ratifica que as empresas não buscam uma melhor gestão ambiental por algum altruísmo que possam ter, ou pela sua repentina preo- 
cupação com os problemas ambientais. Os objetivos das empresas continuam sendo os mesmos, focados em resultados, lucros, liderança, sobrevivência no longo prazo, ampliação de mercado, dentre outros. Para que as empresas possam continuar realizando esses objetivos, elas são forçadas a melhorar o seu desempenho ambiental. Souza (2000) sintetiza os principais condicionantes da postura ambiental em quatro fatores: a) a necessidade de reduzir custos; b) a necessidade de manter-se em dia com as regulamentações ambientais; c) a possibilidade de melhorar a imagem da empresa, e d) a necessidade de desenvolver produtos mais saudáveis e de melhor qualidade.

Porter e Linde (1999) relacionam meio ambiente com competitividade. Para os autores, considerando que a tecnologia se encontra em constante processo de mudança, o novo paradigma da competitividade global realça a capacidade de inovação empresarial, entrelaçando a melhoria ambiental com competitividade. "O progresso ambiental exige que as empresas sejam inovadoras para aumentar a produtividade dos recursos -e é exatamente nesse ponto que se situam os novos desafios da competitividade global" (Porter e Linde, 1999: 395), ou seja, a competição internacional mudou nas últimas décadas, evidenciando, no entendimento de Porter e Linde, que melhorias na gestão ambiental são um bom negócio.

Schmidheiny (1992), ao discutir o desenvolvimento sustentável como atividade empresarial em 1992, indica que as empresas estão se comunicando mais abertamente com seus stakeholders. Nas palavras de Ben Woodhouse, elas estão começando a entender que "o grau de avaliação positiva ou negativa com que uma empresa é julgada, quanto à sua participação na resolução das questôes de sustentabilidade, determinará, em larga medida, a sua viabilidade em longo prazo" (apud Schmidheiny, 1992: 11).

O desafio ambiental se ampliou da poluição local para as ameaças globais. Nesse contexto, o desafio empresarial associado ao desenvolvimento sustentável, no entendimento de Schmidheiny (1992), será alcançado mediante a cooperação entre pessoas e todas as suas diversas organizaçōes, incluindo-se as empresas privadas e os governos. A cooperação entre pes- soas e organizações também é apontada por Souza (2000: 421), ao discutir a questão ambiental e as empresas, sendo que "a solução dos problemas ambientais não se encontra no nível de um ou outro agente econômico apenas, mas dispersa entre todos os agentes econômicos e sociais, no mundo". Em outros termos, a gestão ambiental, na busca de um desenvolvimento sustentável, parte de iniciativas de governos, ações das comunidades locais, ações multilaterais e internacionais e ações das próprias empresas.

\section{Análise da gestão ambiental da indústria fumageira}

Para o levantamento dos dados, tanto para os econômicos como os relativos a práticas de gestão ambiental, recorreu-se metodologicamente a várias evidências, como: a) análise bibliográfica e de documentos, nos quais foram acessadas pesquisas específicas realizadas para o setor, pela Universidade de Santa Cruz do Sul (UNISC) e pela Universidade Federal de Santa Maria (UFSM), Relatórios de Atividades da Associação dos Fumicultores do Brasil (Afubra), Jornais Informativos do Sindicato da Indústria do Fumo (Sindifumo), Anuários Brasileiros do Fumo, Balanços e Relatórios Sociais e Ambientais de empresas que os elaboram e publicam, bem como reportagens de jornais locais; b) entrevistas com representantes da Afubra e Sindifumo, dirigentes executivos de algumas empresas fumageiras e produtores vinculados, e c) observação direta, no qual foram visitadas algumas propriedades de fumicultores, com o objetivo de verificar in loco as práticas ambientais adotadas pela indústria fumageira, especificamente as relativas ao Sistema Integrado de Produção (SIP), objeto de análise do presente estudo.

\subsection{Uma descrição da fumicultura na regiāo sul do Brasil}

Dada a importância econômica do setor fumageiro na Região do Vale do Rio Pardo do Estado do Rio Grande do Sul, bem como nos demais Estados da região Sul do Brasil, apresentam-se inicialmente alguns dados gerais sobre a fumicultura nessa região, integrada pelos Estados do Rio Grande do Sul (RS), Santa Catarina (SC) e Paraná (PR).

O setor fumageiro integra fortemente a economia regional do Vale do Rio Pardo, bem como a economia da região Sul do Brasil, compreendida pelos Estados 
do Rio Grande do Sul (RS), Santa Catarina (SC) e Paraná(PR), contribuindo significativamente para a geração de empregos e renda. A produção de fumo dos três Estados do Sul vem evoluindo a cada safra, conforme demonstrado no Quadro 1, totalizando na safra 2004-2005, 3 bilhões e 650 milhões de reais para 198.040 produtores de 789 municípios, conforme pode ser visualizado na Figura 1, proporcionando uma renda média bruta familiar de $\mathrm{R} \$ 18.431,35$. A cultura do fumo se caracteriza pela produção familiar e absorção maciça de mão-de-obra em pequenas propriedades, situadas em grande parte em regiōes de topografia acidentada, o que dificulta a mecanização (Anuário Brasileiro do Fumo, 2005). Segundo Vogt (2000), dada a sua característica de produção, de não exigir mecanização e de necessitar apenas de uma pequena fração de terra da propriedade, a fumicultura torna-se, muitas vezes, a única alternativa de manutenção de agricultores no campo.
Outra característica da cultura do fumo é o curto ciclo da lavoura, que permite que a mesma terra seja ocupada com duas culturas durante o ano, ocupando em média $16 \%$ da propriedade, representando $67 \%$ da renda familiar. É possível, após a colheita do fumo, o plantio do milho ou feijão de safrinha, aproveitando o resíduo da fertifização, o que resulta numa cultura com baixo custo de produção.

Com o objetivo de conhecer o perfil dos fumicultores da região sul do Brasil, vem promovendo desde o ano de 2002, a cada biênio, um levantamento sócio-econômico dos seus associados. Esse levantamento é realizado pelo Núcleo de Pesquisa Social da Universidade de Santa Cruz do Sul, por meio de uma amostra representativa, selecionada aleatoriamente entre os produtores associados $\mathrm{da}$ Afubra em cada biênio, considerando-se uma mar-

Figura 1. Municípios produtores de fumo na Regiāo Sul.

\title{
Legenda
}

- Municípios produtores

- Municípios não produtores

- Município de Santa Cruz do Sul

\section{Ranking municipal de produção}

\author{
Venâncio Aires \\ Candelária \\ Canguçu \\ Camaquã \\ São Lourenço do Sul
}

Fonte: Afubra (2006)

Quadro 1. Evolução da produção de tabaco nas últimas safras na Região Sul do Brasil.

\begin{tabular}{|c|c|c|c|}
\hline Safras & Famílias produtoras & Hectares plantados & Toneladas produzidas \\
\hline $01 / 02$ & 153.130 & 304.510 & 635.110 \\
\hline $02 / 03$ & 170.830 & 353.810 & 600.540 \\
\hline $03 / 04$ & 190.270 & 411.290 & 851.060 \\
\hline $04 / 05$ & 198.040 & 439.220 & 842.990 \\
\hline
\end{tabular}

Fonte: Anuário Brasileiro do Fumo (2005). 
Figura 2. Linhas de exploração do fumicultor na região Sul do Brasil.

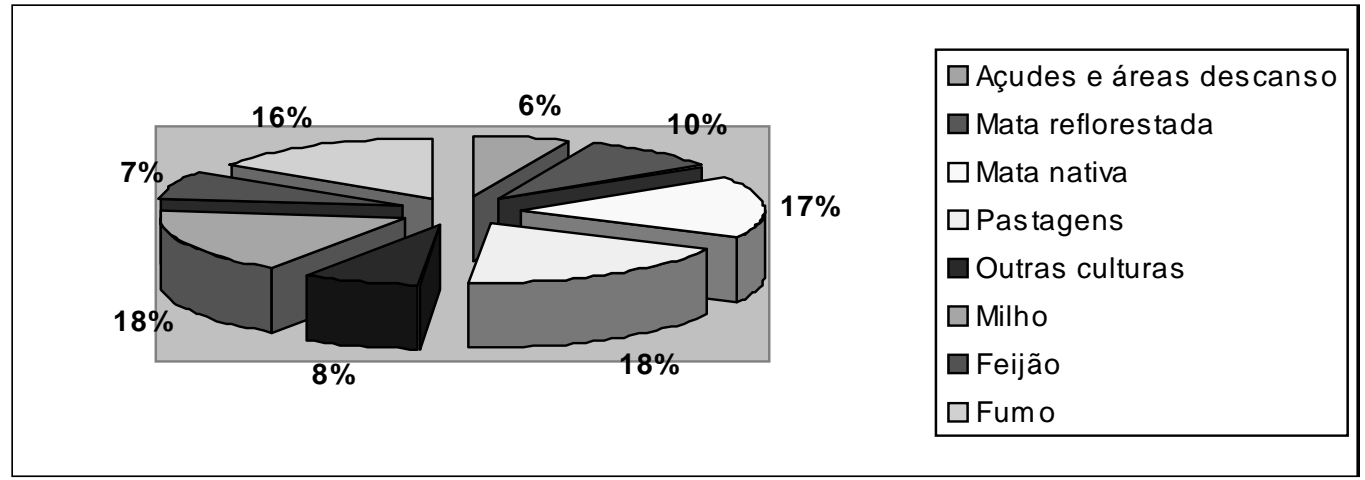

Fonte: Nupes/Unisc (2004).

gem de erro da amostra de 3,5\% e um nível de confiança de $95 \%$. Segundo os resultados do levantamento de 2004, a exploração das propriedades minifundiárias, com área em média de 16,9 hectares, é bem diversificada, conforme pode ser visualizado na Figura 2.

Em termos ambientais, uma significativa parcela da propriedade é destinada para mata nativa e reflorestada, em média $27 \%$, totalizando um percentual superior ao exigido pela legislação brasileira, a título de reserva legal. Conforme legislação, todas as propriedades devem ter $20 \%$ de suas áreas cobertas com florestas, podendo ser áreas nativas, reflorestadas, de erva-mate, de pomar, ou de qualquer outra espécie. A área destinada ao cultivo do fumo representa em média 16\% da propriedade, sendo a maior parte ocupada por outras culturas, principalmente pelo milho e feijão.

Os levantamentos realizados nas duas pesquisas realizadas pelo Nupes/Unisc mostram que a maioria dos produtores possui uma agricultura diversifica, tendo a sua disposição 2.672.550 hectares de terra, nos quais apenas, $16 \%$ em média, é ocupada pelo fumo, sendo uma boa parte destinada a outras culturas, como o milho, feijão, soja, mandioca e hortifrutigranjeiros, ocupando essas em média 35\% da área da propriedade. Outro fato destacado pelo setor é a parceria de 39.650 famílias produtoras que não possuem terra e trabalham em regime de parceira, encontrando na fumicultura uma forma de se

Quadro 2. Números gerais da fumicultura sul-brasileira safras (2003-2004 e 2004-2005).

\begin{tabular}{|l|c|c|c|}
\hline Especificação & UNIDADES & Safra 2003-2004 & Safra $2004-2005$ \\
\hline Municípios produtores & unidades & 759 & 787 \\
\hline No de propriedades & unidades & 152.650 & 158.390 \\
\hline Famílias produtoras & unidades & 190.270 & 198.040 \\
\hline Pessoas ocupadas & unidades & 799.140 & 831.770 \\
\hline$N^{o}$ de estufas & unidades & 167.090 & 185.810 \\
\hline Área das propriedades & hectares & 2.635 .250 & 2.672 .550 \\
\hline Cobertura florestal & hectares & 713.380 & 711.100 \\
\hline Área com outras culturas & hectares & 1.510 .580 & 1.522 .230 \\
\hline Área com fumo & hectares & 411.290 & 439.220 \\
\hline Toneladas produzidas & toneladas & 851.060 & 842.990 \\
\hline Preço médio do fumo & $\mathrm{R} \$ /$ Kg & 4,24 & 4,33 \\
\hline Valor bruto da safra de fumo & $\mathrm{R} \$$ & 3.608 .494 .400 & 3.650 .146 .700 \\
\hline Valor da produção vegetal/animal & $\mathrm{R} \$$ & 1.542 .190 .000 & 1.753 .535 .690 \\
\hline Valor bruto total & $\mathrm{R} \$$ & 5.150 .684 .400 & 5.403 .682 .390 \\
\hline Valor bruto total por família & $\mathrm{R} \$$ & $27.070,40$ & $27.285,81$ \\
\hline Valor/ha da produção vegetal/animal & $\mathrm{R} \$$ & $1.020,93$ & $1.151,95$ \\
\hline Valor por hectare de fumo & $\mathrm{R} \$$ & $8.773,60$ & $8.310,52$ \\
\hline Produtividade/fumo & $\mathrm{Kg} / \mathrm{hectares}$ & 2.069 & 1.919 \\
\hline Tamanho das propriedades & hectares & 17,3 & 16,9 \\
\hline Fon Afubr (2006) & & \\
\hline
\end{tabular}

Fonte: Afubra (2006). 
integrarem ao meio rural (Anuário Brasileiro do Fumo, 2005). No Quadro 2 podem ser visualizados números gerais da fumicultura sul-brasileira, referentes á safra 2003-2004 e 2004-2005.

Segundo dados do Sindifumo (2004), o Brasil é o maior exportador de fumo em folha do mundo, com compradores em mais de 70 países, e o segundo no ranking dos maiores produtores, superado apenas pela China. A produção do fumo se concentra nos três Estados do Sul do Brasil: Rio Grande do Sul, Paraná e Santa Catarina. Entre os maiores produtores de fumo do Estado do Rio Grande do Sul encontram-se os municípios de Venâncio Aires, Candelária e Santa Cruz do Sul, concentrando o maior complexo de beneficiamento de fumo do mundo.

Economicamente as empresas do setor fumageiro se destacam no ranking das 500 maiores exportadoras brasileiras, o que assegurou em 2005, para Santa Cruz do Sul conhecida como a capital do fumo, o segundo lugar como município que mais exportou no Estado do Rio Grande do Sul. No Quadro 3 são apresentados dados gerais da evolução da produção e exportação do fumo na região sul do Brasil, referente ao período de 1995 a 2005 e no Quadro 4 a posição das empresas fumageiras da região do Vale do Rio Pardo que estão entre as 500 maiores exportadores do Brasil.

Além do aspecto das exportações, de acordo com Afubra (2004), o setor fumageiro presta importante contribuição social, envolvendo mais de 2,4 milhōes de pessoas no seu processo, dos quais $37,7 \%$ referem-se a empregos diretos na lavoura, $1,7 \%$ na indústria e $60,6 \%$ são ocupações que de alguma forma estão vinculadas ao setor, como transportadores, fabricantes e distribuidores de insumos agrícolas e fornecedores de matéria-prima.

A fumicultura compõe um grupo muito homogêneo, principalmente pelo fato das empresas adotarem o sistema integrado de produção, único na

Quadro 3. Produção e exportação de fumo no sul do Brasil (1995-2004).

\begin{tabular}{|c|c|c|c|c|}
\hline Safras & $\begin{array}{c}\text { Área } \\
\text { plantada } \\
\text { (hectares) }\end{array}$ & $\begin{array}{c}\text { Toneladas } \\
\text { produzidas }\end{array}$ & $\begin{array}{c}\text { Toneladas } \\
\text { exportadas }\end{array}$ & $\begin{array}{c}\text { Faturamento } \\
\text { Mil US\$/FOB }\end{array}$ \\
\hline 1995 & 206.392 & 341.304 & 231.780 & 732.392 \\
\hline 1996 & 229.470 & 402.159 & 258.270 & 985.871 \\
\hline 1997 & 268.909 & 543.203 & 306.155 & 1.056 .604 \\
\hline 1998 & 265.812 & 403.346 & 291.125 & 960.594 \\
\hline 1999 & 268.388 & 548.760 & 334.306 & 894.790 \\
\hline 2000 & 251.328 & 527.750 & 340.000 & 857.000 \\
\hline 2001 & 252.365 & 504.728 & 414.552 & 962.932 \\
\hline 2002 & 305.551 & 636.871 & 471.991 & 1.066 .593 \\
\hline 2003 & 361.712 & 600.325 & 465.473 & 1.130 .700 \\
\hline 2004 & 411.290 & 851.060 & 587.915 & 1.488 .107 \\
\hline 2005 & 439.220 & 842.990 & $610.000^{*}$ & $1.600 .000^{*}$ \\
\hline
\end{tabular}

* Estimativa

Fonte: Afubra (2006).

Quadro 4. Posição das principais empresas fumageiras no ranking brasileiro das exportações (2005).

\begin{tabular}{|clc|}
\hline Posição & Empresa & US\$ (milhões) \\
\hline $37^{\circ}$ & Universal Leaf Tabacos Ltda. & 502,27 \\
\hline $54^{\circ}$ & Aliance One & 362,48 \\
\hline $63^{\circ}$ & Souza Cruz S.A. & 298,81 \\
\hline $116^{\circ}$ & CTA -Continental Tobaccos Alliance S.A. & 161,30 \\
\hline $188^{\circ}$ & Meridional de Tabacos Ltda. & 89,56 \\
\hline $278^{\circ}$ & Brasfumo -Indústria Brasileira de Fumos Ltda. & 59,90 \\
\hline $307^{\circ}$ & KBH\&C Tabacos Ltda. & 54,14 \\
\hline $329^{\circ}$ & A.T.C -Associated Tobacco Company (Brasil) Ltda. & 48,97 \\
\hline $366^{\circ}$ & Premium Tabacos do Brasil & 43,66 \\
\hline $429^{\circ}$ & Philip Morris Brasil Ind. e Com. Ltda. & 35,66 \\
\hline
\end{tabular}

Fonte: Borowsky (2006). 
fumicultura, em termos mundiais. Entretanto, quando se faz referência ao setor, há empresas com atividades diferenciadas, identificando-se aquelas que produzem e beneficiam o fumo, aquelas que apenas produzem o fumo e estão ligadas a uma beneficiadora e empresas que também fabricam o cigarro.

Neste conjunto, o complexo fumageiro do Vale do Rio Pardo, com base no cadastro de fumicultores da Afubra, é formado por aproximadamente 30 empresas, sendo a maioria de pequeno porte, produtoras de fumo para as empresas maiores, beneficiadoras e exportadoras. Apenas duas empresas são cigarreiras, respectivamente a Philip Morris Brasil Ind. e Com. Ltda. e a Souza Cruz S.A. As mais expressivas, estão associadas ao Sindifumo, entidade representativa das empresas do setor, identificadas no Quadro 5. A sede ou matriz dessas empresas concentra-se nos municípios de Santa Cruz do Sul, Venâncio Aires e Vera Cruz. Dada a característica exportadora do setor, a questão ambiental tem recebido a atenção das empresas, fato esse, atestado pela busca crescente da certificação ambiental pela ISO 14.001, conforme demonstrado no Quadro 5, no qual se verifica que $50 \%$ das empresas mais expressivas do setor, já obtiveram a referida certificação ambiental.

Além da certificação ambiental, o Sindifumo, como entidade representativa das empresas fumageiras, envolve-se em questões sociais e ambientais que afetam o setor. Em parceria com Afubra, o Sindifumo desenvolve ações que estimu- lam o reflorestamento e a preservação das matas nativas em propriedades rurais envolvidas no cultivo de fumo e mantém um programa de coleta itinerante de embalagens de agrotóxicos pelos municípios gaúchos produtores de fumo. Com essa integração Indústria/Sindifumo/Afubra, o setor fumageiro, nos últimos anos, vem reforçando sua política de preservação ambiental.

\subsection{Política ambiental da indústria fumageira}

Uma das particularidade do setor é o processo vinculativo do fumicultor com a indústria fumageira, já que esta exerce influência direta sobre a produção primária do fumo, através do sistema integrado de produção. Muitas das iniciativas, junto ao fumicultor, visam à preservação do meio ambiente, reforçando a importância da gestão ambiental do setor. Na Figura 3 pode-se visualizar a dimensão do sistema integrado de produção de fumo, baseado em sete princípios, que inclui desde planejamento das safras, assistência técnica e financeira, uso de insumos de alta qualidade, garantia de compra total da safra contratada, levantamentos de custos e negociação de preço, programas de responsabilidade social e procedimentos de preservação ambiental.

O sistema integrado na fumicultura teve sua origem por volta de 1918, quando a empresa Souza Cruz instalou uma de suas subsidiárias no município de Santa Cruz do Sul (Vogt, 2000). Conforme estudos do autor, esse processo de integração vertical entre produtor e agroindústria consolidou-se no final dos anos 60, quando a fumicultura registrou um

Quadro 5. Principais empresas fumageiras da região do Vale do Rio Pardo.

\begin{tabular}{|l|c|}
\hline Empresas fumageiras & Certificação \\
\hline ISO 14001 & \\
\hline A.T.C. -Associated Tobacco Company (Brasil) Ltda. & \\
\hline BRASFUMO -Indústria Brasileira de Fumos Ltda. & \\
\hline CTA -Continental Tobaccos Alliance S.A. & $\mathrm{X}$ \\
\hline DIMON do Brasil Tabacos Ltda. & \\
\hline INTAB -Indústria de Tabacos e Agropecuária Ltda. & $\mathrm{X}$ \\
\hline Industrial Boettcher de Tabacos Ltda. & $\mathrm{X}$ \\
\hline Kannenberg \& Cia. Ltda. & $\mathrm{X}$ \\
\hline KBH\&C Tabacos Ltda. & $\mathrm{X}$ \\
\hline Meridional de Tabacos Ltda. & $\mathrm{X}$ \\
\hline Philip Morris Brasil Ind. e Com. Ltda. & \\
\hline Souza Cruz S.A. & \\
\hline Sul América Tabacos S.A. & $\mathrm{X}$ \\
\hline Universal Leaf Tabacos Ltda. & \\
\hline Premium Tabacos do Brasil & \\
\hline
\end{tabular}

Fonte: Dados da pesquisa. 
aumento significativo na região Sul do Brasil, com a ampliação do parque industrial e com o incremento da produção e exportação de fumo.

No que se refere à política ambiental vinculada ao sistema integrado de produção, o setor fumageiro vem atuando: a) na redução da quantidade de agrotóxicos em lavouras de fumo; b) no recolhimento de embalagens de agrotóxicos; c) na orientação sobre o correto uso, manejo e a conservação do solo e dos recursos hídricos; e d) no fomento ao reflorestamento e incentivo à preservação das matas nativas. Esses procedimentos, objeto de análise deste estudo, possuem impacto direto na produção do fumo, no qual o produtor, e neste caso, caracterizado pela agricultura familiar, está condicionado ao padrão tecnológico e ambiental da indústria com o qual possui vínculo.

\subsubsection{Redução da quantidade de agrotóxicos em lavouras de fumo}

Em termos de redução de agrotóxicos, pode-se citar a eliminação do uso do Brometo de Metila, prejudicial à camada de ozônio. Acordos ambientais fixaram o ano de 2010 como o ano em que o Brometo de Metila, utilizado em inúmeras outras culturas agrícolas na esterilização dos solos para a produção de mudas, deve deixar de ser produzido comercialmente. O Brasil reduziu esse prazo para 2005 e o setor fumageiro do Sul do Brasil resolveu antecipar esse prazo em dois anos, encerrando o uso do produto em 2003. Para substituir o Brometo de Metila, o setor fumageiro desenvolveu tecnologias alternativas, como o sistema Float e, mais recentemente, o "Leito de Substrato". Segundo declarações divulgadas pelo setor, o fumo é uma das culturas de interesse econômico que menos utiliza agrotóxicos, resultado de um intenso trabalho para reduzir a quantidade de ingrediente ativo, tanto na produção de mudas como na própria lavoura.

A opção preferencial deverá ser o sistema Float, em que o cultivo é feito em bandejas de isopor com substrato mantidas sobre uma fina lâmina de água. Esse método já vem sendo utilizado pela fumicultura nacional nas últimas seis safras e, em 2003, já abrange $90 \%$ da área produtiva (Anuário Brasileiro do Fumo, 2003). Dada a adoção em lar-

Figura 3. Sistema integrado de produção.

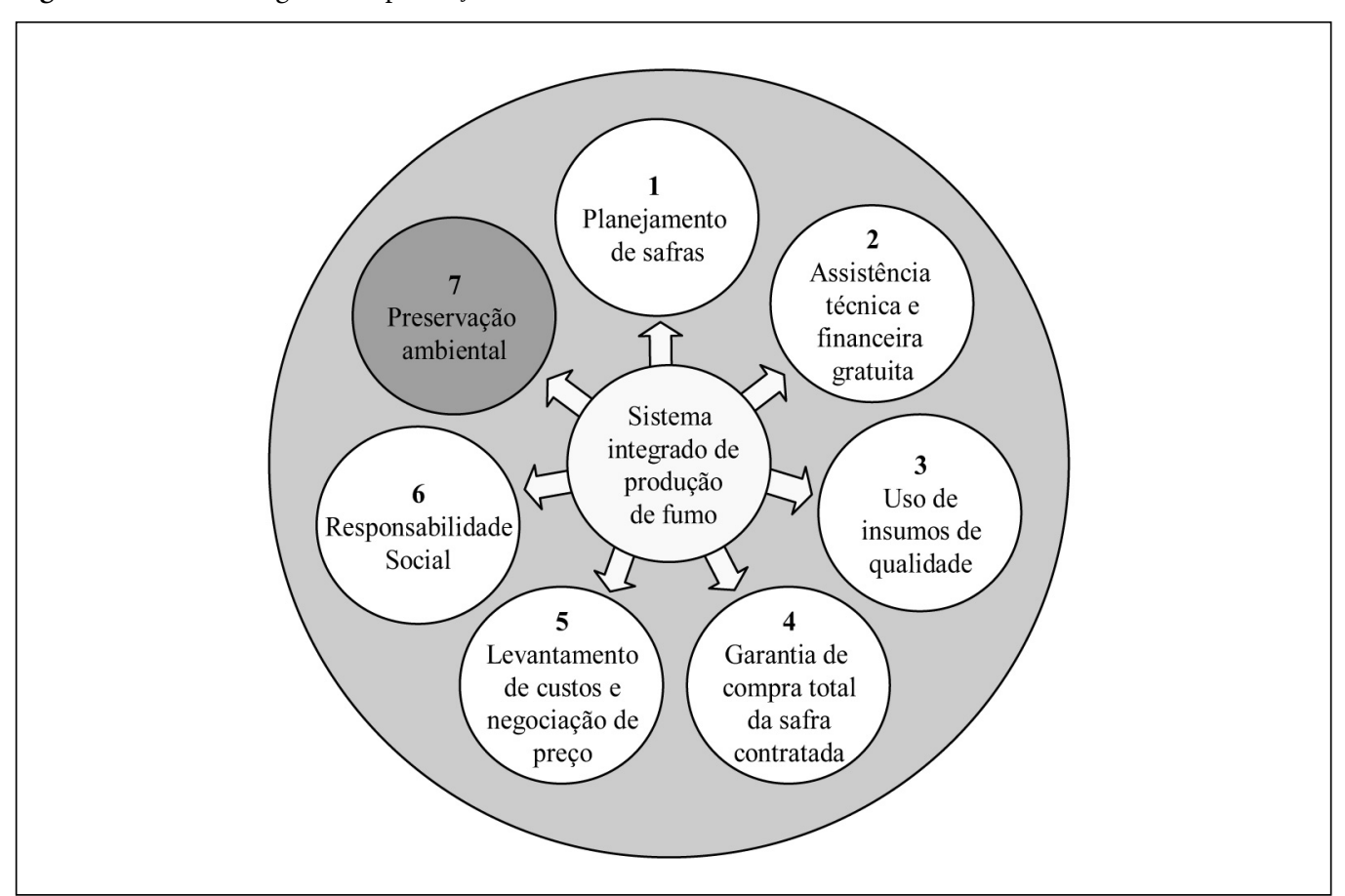

Fonte: Adaptado Sindifumo (2004). 
ga escala do sistema Float, o próprio setor vem buscando, desde já, alternativas para o destino das bandejas de poliestireno expandido (EPS), mais conhecido como isopor. A durabilidade das bandejas é de cinco anos. O setor fumageiro também está buscando parceria com a Abrapex, a associação brasileira que congrega 12 empresas produtoras dessas bandejas, para estabelecer um programa de reaproveitamento das embalagens de EPS. Já existem iniciativas de reciclagem de EPS para a produção de concreto leve.

A alternativa mais recente que vem sendo implementada é o cultivo sobre "Leito de Substrato" que consiste na produção das mudas em material feito a partir da casca do pinus compostada, resíduo da indústria de celulose, o qual dispensa do uso de bandejas de isopor, cujo método vem sendo testado com sucesso há mais de cinco anos. Tanto o sistema Float de produção de mudas, utilizado por quase $90 \%$ dos produtores, como o "Leito de Substrato", eliminam completamente o uso do Brometo de Metila.

Uma outra iniciativa é a produção de fumo sem agroquímicos, também conhecido como fumo ecológico. O programa é uma parceria entre o Sindifumo, a Afubra, a Fundação Gaia e a Universidade de Santa Cruz do Sul. O objetivo é desenvolver estudos para testar alternativas de produção de fumo Virgínia em comparação aos procedimentos convencionais, com o propósito de reduzir ou até de eliminar agroquímicos no cultivo do fumo, visando à obtenção de um produto quimicamente mais limpo. A experiência teve inicio na safra 2001-2002, sendo que na segunda safra 2002-2003 já foram avaliados os primeiros resultados. Aspectos agronômicos indicam que é possível produzir o fumo com volume e qualidade, porém, economicamente, a produção sem agroquímicos ainda é inviável, uma vez que demanda mais mão-de-obra no controle de ervas daninhas e na aplicação de volumes ampliados de fertilizantes orgânicos, cuja disponibilidade é limitada (Sindifumo, 2002). A expectativa é que serão necessários mais experimentos para se chegar ao produto desejado, em níveis razoáveis de custo e de emprego de mão-de-obra (Anuário Brasileiro do Fumo, 2003).

\subsubsection{Recolhimento de embalagens de agrotóxicos}

A legislação ambiental, em 1999, passou a obrigar os fabricantes a darem destino final para as embalagens vazias de agrotóxicos, por meio de reciclagem ou incineração. Os comerciantes, e nesse caso as indústrias fumageiras, devem receber as embalagens dos produtos devolvidos pelos agricultores, que estão obrigados, por lei, a devolverem os recipientes ao comerciante ou a um local credenciado para o recebimento, logo após a utilização do produto. Com o rigor da legislação ambiental, referente à destinação das embalagens vazias de agrotóxicos, o setor fumageiro se defrontou com o problema da carência de empresas receptoras dessas embalagens no Rio Grande do Sul. Conforme levantamento realizado pelo setor, teve-se conhecimento de uma única empresa do gênero já licenciada pela Fundação Estadual de Proteção Ambiental (FEPAM) para operar no Estado, a Cinbalagens, com sede em Passo Fundo, tendo sido estabelecido um acordo para o recebimento, de forma regular, das embalagens geradas na região fumicultora dos Vales do Rio Pardo e Taquari, a contar do mês de outubro de 2000.

O programa é desenvolvido pelo Sindifumo em todos os municípios produtores de fumo do Rio Grande do Sul, com o apoio da Afubra, do Consórcio Intermunicipal de Recebimento de Embalagens Vazias de Agrotóxicos (Cinbalagens) e do Instituto Nacional de Processamento de Embalagens Vazias (INPEV). A coleta de embalagens é restrita às embalagens que recebem a tríplice lavagem e é realizada de forma itinerante em todos os municípios produtores de fumo, em local, data e horários previamente estabelecidos junto aos produtores e às prefeituras, com ampla divulgação regional. Na primeira etapa do programa, foram recolhidas 510 mil embalagens, sendo que na segunda etapa, referente ao período de 11/2002 a 04/2003, o número de embalagens recolhidas aumentou para 600 mil. O aumento, segundo o Sindifumo (2002), se deve à adesão de novos produtores e ao grande número de embalagens de agroquímicos de outras culturas. $\mathrm{O}$ recolhimento de embalagens de agrotóxicos não se restringe às embalagens de produtos utilizados apenas na cultura do fumo. Dada a diversificação da agricultura desenvolvida pelos fumicultores, o maior número de embalagens refere-se a produtos utilizados em 
outras culturas, incluindo-se também embalagens utilizadas por outros produtores.

\subsubsection{Orientação sobre o correto uso, manejo e conservação do solo e dos recursos hídricos}

O preparo e manejo do solo para a instalação e condução da cultura do fumo também vem sofrendo transformaçōes. Durante as décadas de 70 e 80 predominava o preparo intensivo do solo. No início da década de 90 começou a ser introduzido aos poucos o Cultivo Mínimo, evoluindo para o Sistema de Plantio Direto (SPD). O Cultivo Mínimo é uma fase intermediária entre o preparo convencional e o SPD. O Sistema de Plantio Direto vem sendo incentivado pela indústria, dadas as suas vantagens econômicas e ambientais em comparação com o cultivo convencional, que ainda predomina. Entre as principais vantagens relacionadas à questão ambiental, o SPD auxilia no controle da erosão dos solos, melhora ano após ano a fertilidade e a estrutura dos solos, melhora a qualidade da água e melhora o equilíbrio biológico do solo, favorecendo o desenvolvimento de inimigos naturais de pragas e doenças. O Cultivo Mínimo e o Sistema de Plantio Direto são recomendados, principalmente, para regiōes com declividade, nas quais é comum o plantio do fumo, mas onde a erosão é acentuada. Essas práticas, além das vantagens ambientais, diminuem consideravelmente o gasto com mão-de-obra, o que significa diminuição de custos.

Uma prática que sofreu significativos avanços é a tecnologia de cura do tabaco, realizada em estufas. A preocupação do setor foi reduzir a mão-de-obra por parte do produtor e diminuir o consumo de lenha como fonte de energia para a cura. Outra alternativa que vem sendo testada é a substituição da lenha pelo carvão mineral, cujas práticas seguem os padrões tecnológicos de cada indústria, que individualmente desenvolvem suas pesquisas.

Recentemente, em relação à preservação ambiental, os recursos hídricos também estão recebendo a atenção do setor fumageiro. O Sindifumo e diversas outras entidades assinaram um protocolo de cooperação técnica com o objetivo de somar esforços para buscar alternativas para a melhoria da qualidade da água, do uso, manejo e da conservação do solo e das condiçóes socioambientais de propriedades e microbacias hidrográficas.
4.2.4. Fomento ao reflorestamento e incentivo à preservação das matas nativas

Um dos problemas ambientais apontados para o setor é a emissão de gás através da queima de lenha na cura do tabaco. São utilizados nos três Estados do Sul do Brasil, em média, 1,8 milhão de toneladas de lenha por safra para a cura do tabaco. Para amenizar esse problema, o setor fumageiro, numa ação conjunta do Sindifumo e da Afubra, vem desenvolvendo projetos de reflorestamento junto aos produtores.

Com base no estudo realizado pela Universidade de Santa Maria, solicitado pelo Sindifumo, com apoio da Afubra, a fumicultura quebrou mais um paradigma ambiental. O projeto "Quantificação de carbono e dos nutrientes em florestas de eucalipto de diferentes idades" avaliou a capacidade de seqüestro e de armazenamento de carbono pela floresta de eucalipto. Segundo resultados da pesquisa, a quantidade de carbono lançada na atmosfera pela cultura do fumo é menor do que o gás capturado pelas árvores do reflorestamento (Hoppe, Schumacher e Witschoreck, 2003). Esse seqüestro de carbono é a atividade das plantas de retirar, através da fotossíntese, o gás carbônico da atmosfera e acumulá-lo na forma de biomassa.

O estudo realizado pela Universidade Federal de Santa Maria estimou a existência de um estoque médio de 7,6 milhôes de toneladas de carbono nas florestas de eucalipto das pequenas propriedades de produtores de fumo. Equivale a dizer que as áreas reflorestadas no Sul do Brasil seqüestram em um ano o volume de carbono que a fumicultura, através da queima de lenha na cura do fumo, leva oito anos para produzir (Anuário Brasileiro do Fumo, 2003). O plantio de florestas de crescimento rápido, como o eucalipto, tem se mostrado como uma alternativa viável para o "seqüestro de carbono" excedente na atmosfera.

Segundo dados divulgados pelo Sindifumo (2002), o eucalipto é a espécie mais utilizada em reflorestamento no mundo, detendo o Brasil a maior área plantada, com aproximadamente $50 \%$ da área mundial. Nas pequenas propriedades dos fumicultores, o reflorestamento de eucalipto ocupa, em média, de um a três hectares. Especificamente em termos ambientais, as florestas de eucalipto são grandes produtoras de biomassa que as tornam ex- 
celentes sumidouros de carbono atmosférico, amenizando a pressão sobre as matas nativas remanescentes (Hoppe, Schumacher e Witschoreck, 2003).

Além dessas práticas direcionadas diretamente ao cultivo do fumo, o setor fumageiro vem realizando e apoiando projetos de "educação ambiental". Alguns projetos são açôes conjuntas do setor e outros são específicos de cada indústria, visando, no entanto, objetivos comuns, direcionados a melhorar a qualidade de vida e saúde da população, através de ações que promovam a cidadania, o desenvolvimento sustentável, a preservação e recuperação do meio ambiente.

\section{Considerações finais}

A globalização da economia e os novos paradigmas ambientais aumentaram o comprometimento das empresas com a questão ambiental, como é o caso do setor fumageiro, no qual novas exigências estão sendo implementadas, desde leis provenientes dos Estados e protocolos internacionais, como também exigências de clientes que passam a exigir certificações de qualidade ambiental.

Especificamente na questão ambiental referente ao setor fumageiro, tem-se um grande paradoxo. De um lado há um produto final "cigarro" prejudicial à saúde, cada vez mais controlado e de uso restrito, e de outro, há um processo de produção cada vez mais limpo e ambientalmente correto, reforçado pelo mercado internacional que passa a exigir atestados de que as empresas, os processos e os produtos possuam méritos de gestão ambiental.

Independentemente de algumas indústrias possuírem padrão tecnológico próprio na questão ambiental, dado o sistema integrado de produção, verificam-se ações conjuntas, com o fumicultor, como o programa de recolhimento de embalagens de agrotóxicos e o fomento ao reflorestamento e incentivo à preservação das matas nativas. As práticas ambientais, disseminadas pelo sistema integrado de produção, como a adubação verde, o plantio direto e a produção de fumo de forma ecológica, sem uso de produtos químicos, vêm despertando o interesse dos fumicultores, o que evidencia a sua conscientização e preocupação com o meio ambiente.
Em termos de política ambiental do sistema integrado de produção do fumo no Brasil, a maior conquista foi o compromisso assumido pelo setor fumageiro do Sul do Brasil de não mais comercializar o Brometo de Metila, agente agressivo à camada de ozônio, desde o início de 2004, eliminando assim, seu uso na fumicultura. Dessa maneira, os produtores vinculados passaram a adotar, de maneira integral e definitiva, formas alternativas e menos prejudiciais ao meio ambiente, como o sistema Float de produção de mudas e o sistema "Leito de Substrato", em fase experimental.

Por meio do sistema integrado de produção, base para a relação da indústria com o produtor, verificase que práticas ambientais, como o manejo e a preservação dos recursos naturais, são difundidas num grande contingente de agricultores, num total de 198.040 produtores, na sua maioria donos de pequenas propriedades, distribuídos por 787 municípios nos três Estados da região Sul do País, conforme estimativas da safra 2004-2005. Nesse contexto, mesmo que a política ambiental, presente como um dos princípios do sistema integrado de produção, se configure como uma estratégia para que as empresas possam dar prosseguimento às suas operações, mantendo-se competitivas, por outro lado, essa política contribui para a qualidade de vida e para o desenvolvimento sustentável.

Salienta-se ainda, na questão ambiental, a integração de duas entidades distintas da classe, o Sindifumo, que representa as indústrias, e a Afubra, que representa os interesses dos fumicultores. As duas entidades buscam modelos de produção sustentáveis, com respeito à natureza, através de ações conjuntas voltadas para a preservação do meio ambiente e à melhoria da qualidade das comunidades.

\section{Referências bibliográficas}

Andrade, R. O. de, A. B. de Carvalho e T. Tachizawa (2000). Gestão ambiental: enfoque estratégico aplicado ao desenvolvimento sustentável. São Paulo: Makron Books.

Anuário Brasileiro do Fumo 2002 (2003). Santa Cruz do Sul: Gazeta Santa Cruz do Sul. (2005). Santa

Cruz do Sul: Gazeta Santa Cruz do Sul. 
Associação dos Fumicultores do Brasil (2004). "Tabaco no Brasil”. http://www.afubra.com.br/ institucional.

(2006) "Fumicultura no Brasil -Perfil do fumicultor sul-brasileiro: informaçōes gerais". http://www.afubra.com.br/principal.php? acao $=$ conteudo\&u_id $=1 \& i$ id $=1 \&$ menus site_id=2.

Backer, P. de (1995). Gestão ambiental: a administração verde. Rio de Janeiro: Qualitymark.

Becker, D.F. (2001). "A economia política da regionalização do desenvolvimento contemporâneo". Revista Redes, 3: 7-46.

Bello, C. V. V. (2001). Uma proposta de sistema de gerenciamento empresarial voltado ao desenvolvimento sustentável: a visão integrada, quadro de referência e seus condicionantes e requisitos. Tese Programa de Pós-Graduação em Engenharia de Produção, Universidade Federal de Santa Catarina. Florianópolis: UFSC.

Borowsky, J. A. (2006). "Setor fumageiro é destaque em nível nacional”. Gazeta do Sul, Santa Cruz do Sul, 6-8. Caderno especial: 19-22.

Capra, F. et al. (1999). Gerenciamento ecológico -guia do Instituto Elmwood de Auditoria Ecológica e Negócios Sustentáveis. São Paulo: Cultrix.

Castro, I. E. (1994). "Visibilidade da regiāo e do regionalismo: a escala brasileira em questão". Lavinas, L. et al. (eds.) Integração, região e regionalismo. Rio de Janeiro: Bertrand Brasil: 155169.

Churchman, C. W. (1972). Introdução à teoria dos sistemas. Petrópolis: Vozes Ltda.

Comissão Mundial sobre o Meio Ambiente e Desenvolvimento (1991). Nosso futuro comum. Rio de Janeiro: FGV.

Dias, D. de S. (1985). O sistema de informação e a empresa. Rio de Janeiro: LTC.

Etges, V. E. (2001). "A região no contexto da globalização: o caso do Vale do Rio Pardo". Vogt, O. P. e R. L. L da Silveira (orgs.). Vale do Rio Pardo: (re)conhecendo a região. Santa Cruz do Sul: EDUNISC: 351-365.

Hoppe, J. M., M. V. Schumacher e R. Witschoreck (2003). Quantificação do carbono e dos nutrientes em florestas de eucalipto de diferentes idades. Relatório de pesquisa Fundação de Apoio à Tecnologia e Ciência. Santa Maria: Universidade de Santa Maria (CD-ROM).
Kinlaw, D. C. (1997). Empresa competitiva e ecológica: desempenho sustentado na era ambiental. São Paulo: Makron Books.

Layrargues, P. P. (2000). “Sistemas de gerenciamento ambiental, tecnologia limpa e consumidor verde: a dedicada relação empresa-meio ambiente no ecocapitalismo". Revista de Administração de Empresas, 40, 2: 80-88.

Lerípio, A. A. (2000). Novas metodologias em gestão da qualidade ambiental. Florianópolis: Universidade Federal de Santa Catarina.

Lima, G.F. da C. (1997). "O debate da sustentabilidade na sociedade insustentável". Revista Politica \& Trabalho, 13: 201-222.

Maimon, D. (1996). Passaporte verde: gestão ambiental e competitividade. Rio de Janeiro: Qualitymark.

Mattedi, M. A. e I. M. Theis (2002). "Cruzando fronteiras: conhecimento e interdisciplinaridade na pesquisa em desenvolvimento regional". $R e-$ vista Redes, 7, 2: 77-94.

Núcleo de Pesquisa Social da Universidade de Santa Cruz e Sul (2004). Diagnóstico sócio-econômico dos pequenos produtores agrícolas no sul do Brasil: uma comparação entre fumicultores e não fumicultores. Santa Cruz do Sul: NUPES.

Porter, M. E. e C. Van der Linde (1999). "Verde e competitivo". Porter, M. E. (ed.), Competição $=$ on competition: estratégias competitivas essenciais. Rio de Janeiro: Campus: 371-397.

Revista Meio Ambiente Industrial (2003). São Paulo: Editora Tocalino Ltda., 8, 43, 42.

Sanches, C. S. (2000). "Gestão ambiental proativa”. Revista de Administração de Empresas, 40, 1:7687.

Schmidheiny, S. (1992). Mudando o rumo: uma perspectiva empresarial global sobre desenvolvimento e meio ambiente. Rio de Janeiro: FGV.

Seiffert, M. E. B. (2002). Modelo de implantação de sistemas de gestão ambiental (SGA-ISO 14001) utilizando-se a abordagem da engenharia de sistemas. Tese Programa de Pós-Graduação em Engenharia de Produção, Universidade Federal de Santa Catarina. Florianópolis: UFSC.

Sindifumo (2002). Jornal Informativo do Sindicato da Indústria do Fumo. Santa Cruz do Sul, 6, 8. (2004). "A maior safra de fumo da história do Brasil". Gazeta do Sul, Santa Cruz do Sul, 14-15 fev. Gazeta Rural: 2-3. 
Souza, R. S. de (2000). Entendendo a questão ambiental: temas de economia, politica e gestão do meio ambiente. Santa Cruz do Sul: EDUNISC.

Theis, I. M. e M. H. P. Renck (2002). "A insustentabilidade socioambiental do desenvolvimento regional no Brasil: análise crítica do caso da seca na região do extremo oeste de Santa
Catarina”. IV Colóquio sobre Transformaçōes Territoriais, Montevideo: 1-18 (CD-ROM).

Vogt, P. O. (2000). "Produtor integrado: um apêndice da exploração industrial”. Centro de Estudos Marxistas, Os trabalhos e os dias: ensaios de interpretação marxista. Passo Fundo: UPF. 